\title{
Prednisone for chronic active liver disease: dose titration, standard dose, and combination with azathioprine compared ${ }^{1,2}$
}

\author{
W. H. J. SUMMERSKILL 3 , MELVYN G. KORMAN 4 , HELMUT V. AMMON, \\ AND ARCHIE H. BAGGENSTOSS \\ From the Gastroenterology Unit and Department of Pathology, Mayo Clinic and Mayo Foundation, \\ Rochester, Minnesota, U.S.A.
}

SUMMARY Among 120 consecutive patients with chronic active liver disease (CALD) randomized to different treatments, those receiving maintenance doses of prednisone $20 \mathrm{mg}$ daiiy (Pred), prednisone in doses given on alternate days and titrated to secure resolution of clinical and biochemical abnormalities (Pred-Titrad), or a combination of prednisone $10 \mathrm{mg}$ and azathioprine $50 \mathrm{mg}$ daily (Comb) survived and underwent resolution of clinical and biochemical features of disease more often than a control group receiving placebo or azathioprine $100 \mathrm{mg}$ daily. Histological remission occurred significantly more often with Pred and Comb than with other regimens. Major side-effects of therapy were commoner with Pred than with Comb or Pred-Titrad, which did not differ. We conclude that Comb is the initial treatment of choice for CALD, since clinical, biochemical, and histological resolution of disease activity occurs as often as with Pred, whereas early side-effects are significantly less frequent.

Advances in treatment of the related conditions comprising chronic active liver disease (CALD) include three recent controlled trials with steroids, azathioprine, or both. Cook and associates (1971) showed that variable doses of prednisolone (from 10 to 2.5 $\mathrm{mg}$ daily) improved certain liver function tests and survival. Therapy with prednisone $15 \mathrm{mg}$ daily was found by Murray-Lyon and his colleagues (1973) to be more effective than azathioprine $75 \mathrm{mg}$ daily for increasing the life expectancy of patients with chronic active hepatitis with or without cirrhosis. We showed that daily maintenance with prednisone 20 $\mathrm{mg}$, or a combination of prednisone $10 \mathrm{mg}$ with azathioprine $50 \mathrm{mg}$, were not only equally successful in improving survival but also secured clinical, biochemical, and histological remission of disease features significantly more often than azathioprine

'Supported in part by Grants AM-6908 and AM-5259 from the National Institutes of Health, Bethesda, MD and a Grant-in-Aid from the Wellcome Foundation.

${ }^{2}$ Presented before the International Association for the Study of the Liver, Acapulco, 1974.

${ }^{3}$ Address for reprint requests : Dr. W. H. J. Summerskill, Mayo Clinic,

Rochester, MN 55901, U.S.A.

'Dr. M. G. Korman is an Eli Lilly International Fellow.

Received for publication 31 July 1975.
(100 mg) or placebo (Soloway et al., 1972). In all these studies, medications were initially prescribed in larger amounts and the benefits of therapy outweighed toxic side-effects due to the drugs.

As in previous reports of treatment of CALD, choices of drug schedules were empirical in the studies cited. Standardized doses were employed in two (Soloway et al., 1972; Murray-Lyon et al., 1973) but the amounts prescribed were adjusted in the third (Cook et al., 1971). The precedent for such 'dose-titration' of steroids to differing maintenance regimens had been established earlier (Mackay, 1968; Mistilis, 1969; Page et al., 1969), although the rationale and specific procedures involved have never been detailed. These presumably take into account clinical responses, evaluation of liver function tests, and side-effects due to medications. Measures reducing drug toxicity associated with steroids are particularly desirable, providing therapeutic efficacy is preserved. Appropriate downward titration of the amount of prednisone given (Mackay, 1968; Mistilis, 1969; Page et al., 1969) embodies this principle and, in conditions other than liver disease, the side-effects of steroids appear also to be reduced without prejudicing their therapeutic actions by prescribing 
'double doses' on alternate days (Harter et al., 1973; Siegel et al., 1972).

This report (1) compares the effects of prednisone given on alternate days in doses titrated by a standard mechanism to achieve resolution of symptoms, abnormal liver function tests and histological features of disease activity with those of treatments earlier used by us (Soloway et al., 1972); and (2) identifies from our treatment programmes the therapy of choice for CALD, as measured by benefits and risks.

\section{Methods}

\section{PATIENTS}

The clinical material comprised 120 consecutive patients meeting our criteria for the diagnosis of severe CALD (Soloway et al., 1972), randomized to one of five treatment schedules during the six years before the current data analysis and followed-up for six months or longer (unless death occurred earlier). Patients were randomized from four subgroups, depending upon the presence or absence of cirrhosis or previous treatment (Soloway et al., 1972).

\section{TREATMENT SCHEDULES}

Treatments were assigned as follows: (a) 16 patients received placebo (Plac) and (b) 13 received azathioprine $100 \mathrm{mg}$ daily (together these form our control group, since responses were shown to be similar (3)); (c) 30 patients received prednisone (Pred) $60 \mathrm{mg}$ daily for one week, $40 \mathrm{mg}$ daily for one week, $30 \mathrm{mg}$ daily for two weeks, and $20 \mathrm{mg}$ daily for maintenance; (d) 30 patients received a combination (Comb) of prednisone and azathioprine, comprising prednisone $30 \mathrm{mg}$ daily for one week, $20 \mathrm{mg}$ daily for one week, $15 \mathrm{mg}$ daily for two weeks, and $10 \mathrm{mg}$ daily for maintenance, in addition to azathioprine $50 \mathrm{mg}$ daily throughout; and (e) 31 patients received prednisone in doses titrated to procure biochemical resolution (see later) of abnormal liver function tests and given on alternate days (Pred-Titrad). This schedule involved initial doses of prednisone identical with Pred, followed by titration and alternate day dosage after three months. The procedure commenced with $10 \mathrm{mg}$ of prednisone on alternate days, selected as comparable with the lower dose of prednisolone often controlling disease activity and prolonging survival (Cook et al., 1971). Thereafter, serum bilirubin, GOT, and gamma globulin were determined from mailed serum specimens every two weeks. When necessary, $10 \mathrm{mg}$ increments of prednisone were given until stabilization of tests with successive values in the biochemical resolution range (see below) had been achieved within the limits of 10-50 mg prednisone on alternate days. The random- ization scheme was statistically adjusted (Soloway et al., 1972) in 1969 for the addition of the fourth treatment group (Comb) and, by an identical procedure, in 1971 to admit the fifth group (Pred-Titrad). Two schedules (azathioprine and placebo) were discontinued in 1971 when shown to be less effective than others and, since responses to these regimens did not differ significantly (Soloway et al., 1972), these patients continue to form a joint control group.

\section{DESIGN OF STUDY}

This paper resembles our initial publication (Soloway et al., 1972), in that only responses to first treatments are analysed, thus differing from some later reports (Ammon et al., 1972; Ammon et al., 1973) recording results of subsequent treatments after relapses. Four patients initially meeting admission criteria, included in our initial report (Soloway et al., 1972), distributed to different treatment schedules, and remaining unchanged by treatment are now excluded. Three developed characteristics of primary biliary cirrhosis and one became an alcoholic during the period of study. Analysis of computerized data bearing on all clinical, biochemical, immunoserological, and histological features of the three treatment groups and the control group show no differences in the characteristics of patients admitted to the programme.

Specific pre-established clinical, biochemical, and histological criteria all had to be met for admission to the programme for predetermined end-points of therapy-remission or treatment failure (Soloway et al., 1972)-and for relapse (Ammon et al., 1973), which called for reinitiation of the same treatment.

Entry to the programme (Soloway et al., 1972) was restricted to post-pubertal patients with documented activity and chronicity of the disease. Activity was defined as SGOT $\geq \times 10$ normal, or SGOT $\geq$ $\times 5$ normal in association with serum gamma globulin $\geq \times 2$ normal, together with histological features of chronic active liver disease (CALD). These comprised chronic active (aggressive) hepatitis (CAH), subacute hepatitis with bridging (SHB), or multilobular necrosis (SHMN)-similar to subacute or submassive hepatic necrosis-or active hepatitis with cirrhosis. Chronicity was determined by continuation without improvement of clinical and biochemical features of disease for at least 10 weeks or by the presence of cirrhosis on liver biopsy.

Remission (Ammon et al., 1972; Soloway et al., 1972) was defined as (1) absence of symptoms and return of the patient to customary activities; (2) return of all liver function and immunoserological tests to normal, apart from SGOT $\times 2$ normal and, in some instances, $\mathrm{HB}_{\mathrm{s}} \mathrm{Ag}$; and (3) normal histological appearances of the liver or features of inactive 
hepatitis with portal tract inflammation, with or without minimal piecemeal necrosis (appearances identical with those in chronic persistent hepatitis). The presence of cirrhosis did not preclude remission of the associated hepatitis. Biochemical resolution (Soloway et al., 1972) comprised the improvements in clinical and laboratory features specified under (1) and (2) above without histological verification of (3).

Remission called for weekly reduction and discontinuation of medications over a six week period. Pred was given in $15 \cdot 0,10 \cdot 0,5 \cdot 0,2.5$, and $2.5 \mathrm{mg}$ daily doses. For Pred-Titrad, decrements from the stabilization dose were made in comparable proportions. For Comb, doses of prednisone were $7 \cdot 5$, $7 \cdot 5,5 \cdot 0,5 \cdot 0,2 \cdot 5$, and $2 \cdot 5 \mathrm{mg}$ daily, azathioprine being given for three weeks and then discontinued. Serum bilirubin, GOT, and gamma globulin were determined on sera sent from home at three, six, nine and 12 weeks after remission. Patients returned immediately for evaluation (including biopsy) if clinical or biochemical features were consistent with relapse.

Relapse (Ammon et al., 1972) comprised SGOT $>\times 3$ normal and the return of morphological features of activity. Treatment failure (Soloway et al., 1972) connoted the onset of endogenous coma, ascites, or elevation of serum bilirubin and GOT at least $66 \%$ above previous values, or side-effects necessitating cessation of medications.

Patients were examined before treatment and always returned at six monthly intervals. Additional visits were necessitated by relapse, treatment failure, or other circumstances. Before therapy and at each visit, the following tests pertinent to biochemical resolution were determined-normal values in parentheses: serum bilirubin $(<1.3 \mathrm{mg} / \mathrm{dl})$; albumin ( $>3.3 \mathrm{~g} / \mu)$; gamma globulin $(<1.8 \mathrm{~g} / \mathrm{dl})$; GOT (< $25 \mu / \mathrm{l})$; alkaline phosphatase $(<60 \mu / \mathrm{l})$; prothrombin time $(<19 \mathrm{~s})$ and hepatitis B surface antigen. In addition, serum bilirubin, albumin, globulin, and GOT were measured from mailed sera two weeks and three months after each treatment course was initiated and (see earlier) at more frequent intervals with Pred-Titrad or after remission. BSP retention was determined before treatment in anicteric patients and to confirm biochemical resolution. Immunoserological tests (antimitochondrial antibody, antinuclear antibody, smooth muscle antibody, LE clot test, and serum immunoglobulin measurements) were performed intially and six monthly until 'normal. All biochemical determinations were made in our diagnostic laboratories, which were unaware of the source of specimens.

Histological evaluation of liver biopsies was undertaken before admission to the programme and then (usually every six months) to verify remission, continued remission, continued activity, relapse, or the cause of treatment failure. Each specimen was coded and evaluated by the same observer without knowledge of other data (Soloway et al., 1971; Soloway et al., 1972). Our original histological classification (Soloway et al., 1972) is unchanged for inactive (chronic persistent) hepatitis, CAH, SHB, or SHMN but differs (Baggenstoss et al., 1972; Summerskill, 1974) for cirrhosis, which earlier included the presence of portions of regenerative nodules (Soloway et al., 1972). Review of sequential coded specimens showed that fibrosis and cirrhosis were not always distinguished by this criterion (Baggenstoss et al., 1972). The diagnosis of cirrhosis now requires the presence of at least one complete regeneration nodule. Further, since the pattern of hepatitis in the presence of cirrhosis is often difficult to classify, such instances are now termed as cirrhosis with active or inactive hepatitis (Baggenstoss et al., 1972; Summerskill, 1974).

Other routine investigations pertinent to the disease, to treatment, or to complications have been specified, as have additional factors involved in management, reasons for exclusion, and contraindications to the use of azathioprine or larger doses of prednisone (Soloway et al., 1972). More recent additions comprise investigations which exclude patients with Wilson's disease, primary biliary cirrhosis, or certain types of drug-induced hepatic lesions which are now known sometimes to mimic the features of CALD (Summerskill, 1974).

Data are analysed for eligible patients, these representing all survivors followed for the appropriate intervals. Chi square and unpaired $t$ tests were used for statistical evaluation.

\section{Results}

RESPONSES TO TREATMENT

Randomization resulted in treatment groups of comparable size and composition with regard to age, sex, and morphological characteristics of the hepatic lesions on entry to the programme (Table 1). Clinical features of liver disease, abnormalities of liver function tests, and immunoserological changes were also comparably distributed and are not detailed, since they resemble those documented earlier (Soloway et al., 1972; Summerskill, 1973). As also earlier reported (Soloway et al., 1972) and confirmed in this larger series, the majority of patients treated with Pred or Comb entered full remission; remission occurred less often in the control group $(P<0.005)$, who failed treatment $(P<0.001)$ and died $(P<0.005)$ more frequently than those receiving other therapies (Table 2).

Patients receiving Pred-Titrad behaved similarly to those allocated to Pred or Comb in that, contras- 


\begin{tabular}{|c|c|c|c|c|c|c|c|c|c|}
\hline \multirow[t]{2}{*}{ Treatment } & \multirow{2}{*}{$\begin{array}{l}\text { Total } \\
\text { no. }\end{array}$} & \multirow{2}{*}{$\begin{array}{l}\operatorname{Sex} \\
M\end{array}$} & \multirow{2}{*}{$F$} & \multirow{2}{*}{$\begin{array}{l}\text { Age }(y r) \\
\text { Mean }( \pm S E)\end{array}$} & \multirow{2}{*}{ Range } & \multicolumn{4}{|c|}{ Histological features } \\
\hline & & & & & & $C A H$ & $S H B$ & $S H M N$ & $C I R R(+A H)$ \\
\hline $\begin{array}{l}\text { Comb } \\
\text { Pred } \\
\text { Pred-Titrad } \\
\text { Control (total) } \\
\quad \text { (Placebo or azathioprine) }\end{array}$ & $\begin{array}{c}30 \\
30 \\
31 \\
29\end{array}$ & $\begin{array}{c}8 \\
11 \\
13 \\
10\end{array}$ & $\begin{array}{c}22 \\
19 \\
18 \\
19\end{array}$ & $\begin{array}{l}44 \pm 3.5 \\
40 \pm 3.6 \\
34 \pm 2.6 \\
38 \pm 3.5\end{array}$ & $\begin{array}{l}13-70 \\
13-75 \\
14-67 \\
12-70\end{array}$ & $\begin{array}{l}5 \\
8 \\
9 \\
5\end{array}$ & $\begin{array}{r}12 \\
7 \\
7 \\
6\end{array}$ & $\begin{array}{l}8 \\
8 \\
9 \\
6\end{array}$ & $\begin{array}{r}5 \\
7 \\
6 \\
12\end{array}$ \\
\hline
\end{tabular}

Table 1 Characteristics of treatment groups before therapy

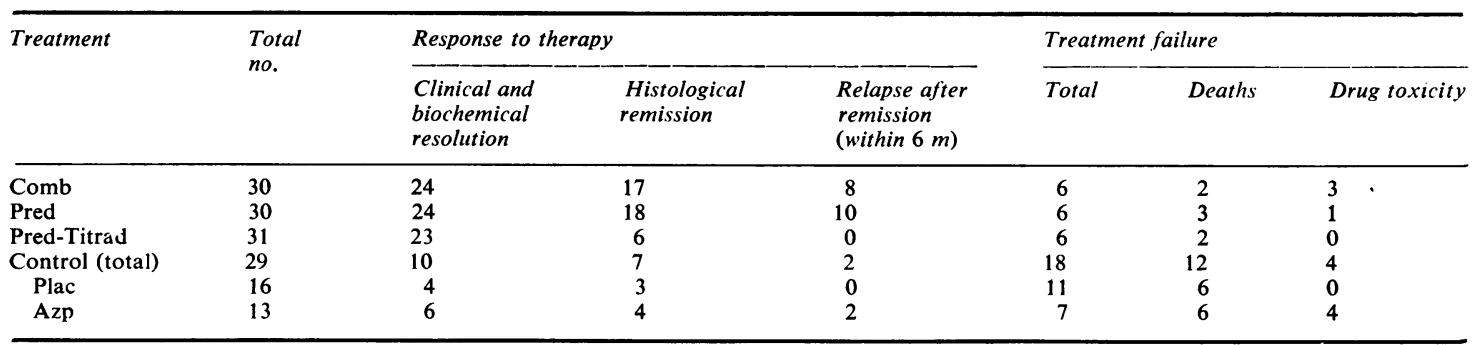

Table 2 Responses to treatment compared in CALD

ted with the control group, the majority underwent biochemical resolution of their disease $(P<0.001)$, but failed treatment $(P<0.01)$ or died less often $(\mathbf{P}<0.01)$. However, Pred-Titrad patients differed from those given Pred or Comb, since disappearance of histological features of active liver disease occurred less frequently $(P<0.005)$ and remission was no commoner than in the control group. Remissions with Pred-Titrad therefore appeared spontaneous rather than drug-induced, especially as there were no relapses during the six months after discontinuation of therapy. Findings were similar in the control group, whereas there was a $50 \%$ incidence of relapse after discontinuation of Pred or Comb ( $<<0.001)$ (Table 2$)$.

TREATMENT FAILURE (Table 2)

Most of the treatment failures (19 of 28 patients, excluding drug toxicity) died from liver disease. With Pred-Titrad, Pred, or Comb (Table 3), 10 of 18 treatment failures occurring during the first six months of therapy were attributable to progressive disease. Findings in the control group were similar and have been specified earlier (Soloway et al., 1972). Drug toxicity sufficiently severe to require rerandomization was infrequent. occurred least often with Pred-Titrad, did not differ greatly among the treatment groups, and is considered later with other side-effects of medications. Two of the patients developing severe complications with Pred are not classified as treatment failures, since the complications coincided with remission and cessation of therapy. Comparable numbers of patients developed cirrhosis during the period of follow-up, this occurring in four patients each in the Pred and Pred-
Titrad groups, five of the control group, and six assigned to Comb.

\section{SEQUENCE OF RESPONSES}

The responses of eligible patients in relation to duration is detailed (Table 3), treatment failures or those with a shorter follow-up being excluded from later analysis. After three months, patients assigned to Pred-Titrad or Pred entered biochemical resolution in comparable numbers, in accord with their identical therapy until then. When titration and the alternate day schedule were then initiated, appropriate doses were found within the next three months since at six months the incidence of biochemical resolution was also similar with Pred-Titrad, Pred, and Comb. During the interim, only six Pred-Titrad patients remained unchanged; the remaining 20 patients required upward adjustments of the dose of prednisone. Among these, 94 analyses of mailed sera were necessary to find the required stabilization dose. By contrast, tests during this period were necessary for only two (treatment failures) of 60 patients assigned to Pred or Comb. The alternate day dose of Pred-Titrad securing biochemical resolution varied from $50 \mathrm{mg}$ (one patient) through 40 or $30 \mathrm{mg}$ (two patients each), and $20 \mathrm{mg}$ (six patients) to $10 \mathrm{mg}$ (nine patients). The mean maintenance dose in these 20 patients was therefore equivalent to exactly $10 \mathrm{mg}$ of prednisone daily.

Comparing Pred-Titrad with Pred and Comb at regular intervals up to 36 months of treatment, the proportion achieving biochemical resolution with each regimen was comparable at all periods of follow-up, and treatment failures were not significantly different. However, Pred or Comb 


\begin{tabular}{|c|c|c|c|c|c|c|c|}
\hline & \multicolumn{7}{|c|}{ Months of follow-up } \\
\hline & 3 & 6 & 12 & 18 & 24 & 30 & 36 \\
\hline \multicolumn{8}{|l|}{ Comb (30) } \\
\hline \multicolumn{8}{|l|}{ Ineligible } \\
\hline $\begin{array}{l}\text { Treatment } \\
\text { Failure }\end{array}$ & 2 & 2 & - & - & 2 & - & - \\
\hline Shorter follow-up & - & - & 3 & - & 1 & - & 3 \\
\hline Eligible & 28 & 26 & 23 & 23 & 20 & 20 & 17 \\
\hline Resolution & 7 & 18 & 19 & 19 & 19 & 20 & 17 \\
\hline Histological remission & - & 1 & 8 & 14 & 16 & 18 & 16 \\
\hline \multicolumn{8}{|l|}{ Pred (30) } \\
\hline \multicolumn{8}{|l|}{ Ineligible } \\
\hline $\begin{array}{l}\text { Treatment } \\
\text { Failure }\end{array}$ & 3 & - & 1 & 1 & - & 1 & 一 \\
\hline Shorter follow-up & - & - & 1 & 2 & 3 & - & 4 \\
\hline \multicolumn{8}{|l|}{ Eligible } \\
\hline Eligible & 27 & 27 & 25 & 22 & 19 & 18 & 14 \\
\hline Resolution & 10 & 16 & 20 & 19 & 18 & 18 & 14 \\
\hline Histological remission & - & 4 & 9 & 11 & 13 & 13 & 11 \\
\hline \multirow{2}{*}{\multicolumn{8}{|c|}{ Pred-Titrad (31) }} \\
\hline Ineligible & & & & & & & \\
\hline Treatment & 1 & 2 & $\mathbf{0}$ & 1 & 2 & - & - \\
\hline $\begin{array}{l}\text { Failure } \\
\text { Shorter follow-up }\end{array}$ & 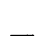 & 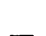 & 6 & 3 & 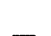 & 4 & 3 \\
\hline Eligible & $\overline{30}$ & $\overline{28}$ & 22 & 18 & $\overline{16}$ & 12 & 9 \\
\hline Resolution & 14 & 17 & 18 & 16 & 14 & 12 & 9 \\
\hline Histological remission & - & 3 & 5 & 4 & 4 & 4 & 3 \\
\hline
\end{tabular}

Table 3 Incidence of resolution (clinical and biochemical) and histological remission during treatment * *Patients who failed treatment or whose follow-up is insufficient are ineligible for subsequent analysis.

induced histological remission much more frequently and the incidence of remission increased with time, affecting $84 \%$ of qualified patients after three years of treatment. By contrast, the incidence of remission with Pred-Titrad was significantly and progressively less at each six month interval after one year $(P<0.001-0.005)$ through the 36 months of followup.

Since the mean dose of prednisone $(10 \mathrm{mg})$ necessary for Pred-Titrad was identical with the dose contained in Comb, the addition of azathioprine (50 mg) is likely to account for the superiority of Comb for inducing histological remission. Most directly comparable is the course of eight patients assigned to Pred-Titrad and stabilized on 20 or $30 \mathrm{mg}$ prednisone on alternate days (thus equivalent to or greater than the prednisone component of Comb, but less than that of Pred). These patients were treated for a mean of $\mathbf{3 0}$ months and only two ( $25 \%$ ) entered histological remission, as compared with 18 of $20(90 \%)$ patients taking Comb for this period of time $(P<0.05)$.

Side-effects of medication Major side-effects attributable to prednisone or azathioprine, including those causing treatment failure (Table 2), are listed (Table 4). Several severe side-effects (gross cosmetic changes, diabetes, hypertension, cataracts, psychosis, duodenal ulcer, osteoporosis with aseptic necrosis of the hip or vertebral collapse) appeared directly related to steroids, since they did not occur in the control group. These complications involved two-thirds of patients allocated to Pred, but were much less common $(P<0.001)$ with Pred-Titrad or Comb. Five patients had more than one complication. The overall incidence of side-effects due to prednisone is underestimated, since minor and more tolerable cosmetic changes (facial rounding, acne, hirsutism, dorsal hump, and obesity) developed in the majority of the remaining patients taking Pred and in some assigned to Comb or Pred-Titrad. Concerning azathioprine, two patients receiving Comb developed severe skin rashes which subsided when azathioprine was discontinued and reappeared when the drug was reintroduced, thus necessitating classification as treatment failure and rerandomization.

By contrast, in the setting of severe CALD, leucopenia or thrombocytopenia clearly cannot always be atttributed to azathioprine, while massive gastrointestinal haemorrhage (haematemesis and/or melaena) is similarly not always related to steroid therapy (Table 4). Thus, five of 11 patients developing thrombocytopenia or leucopenia in fact were on regimens (Pred or placebo) which did not contain azathioprine. And five of eight patients experiencing massive gastrointestinal haemorrhage were receiving treatments (azathioprine or placebo) which did not feature steroids. These various complications were 


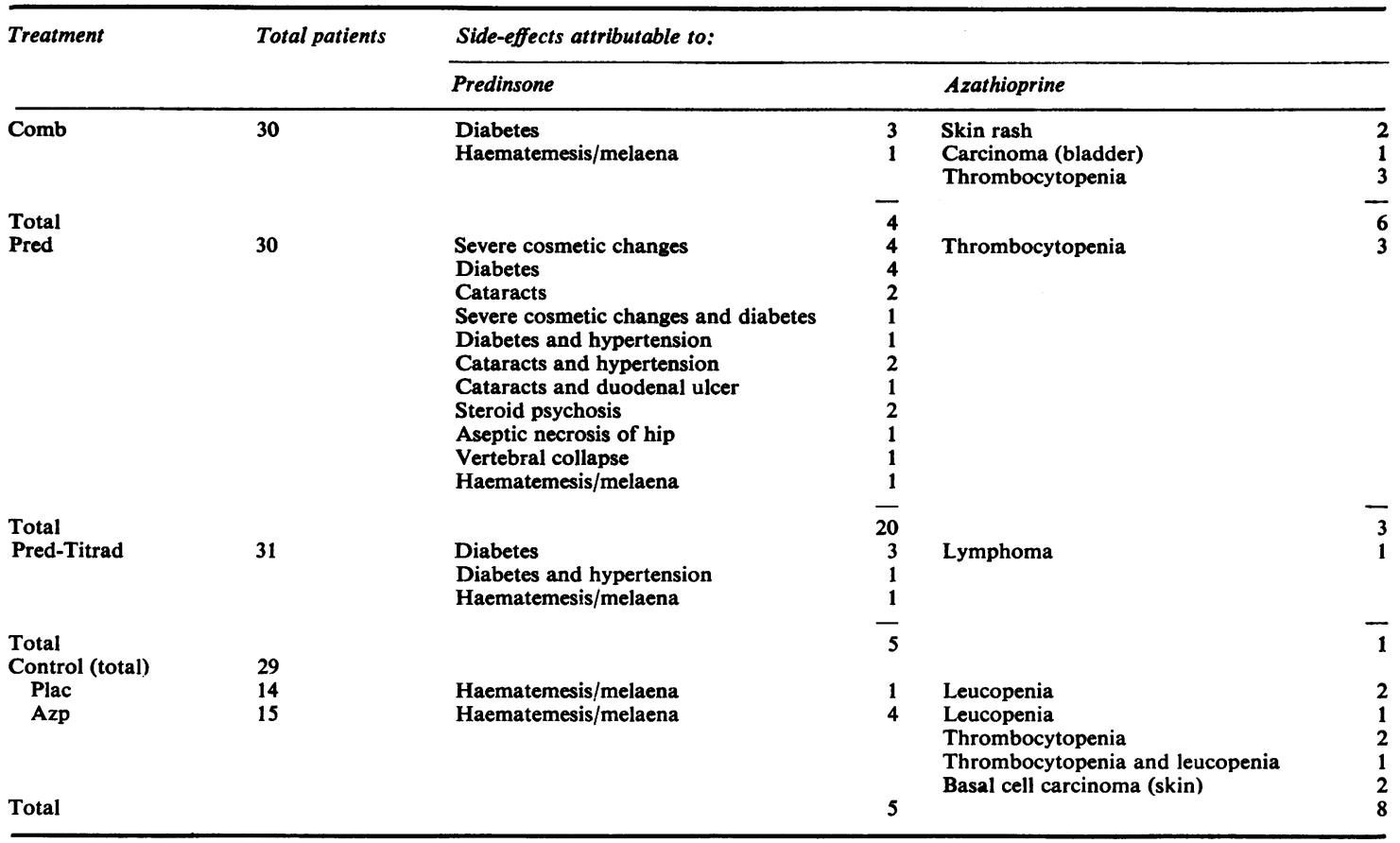

Table 4 Presumed side-effects of therapy

therefore often attributable to the severity of the liver disease and the associated portal hypertension or hypersplenism.

The aetiology of three low grade operable and nonrecurrent carcinomas (two of the skin and one of the bladder) occurring with regimens containing azathioprine also cannot be evaluated, especially as these patients were in a higher risk age group (54, 58 , and 59 years) and the cause of a lymphoma in one patient of a similar age given Pred-Titrad is equally uncertain.

\section{Discussion}

Our results yield two major conclusions. First, in this much larger series of patients with CALD, Pred and Comb not only maintained their earlier therapeutic superiority (Soloway et al., 1972) over Azp and Plac, but Comb can be proposed as the initial treatment of choice because early side-effects are less frequent and severe than those induced by Pred. Second, the commonly employed approach to treatment represented by Pred-Titrad is less effective than Pred or Comb because the dose suppressing symptoms and achieving resolution of abnormal liver function tests without major side-effects infrequently procures histological remission of active liver disease. However, we point out that other schedules employ- ing dose titration or alternative day treatment might be more successful than ours, providing the amount of medication prescribed is determined by factors additional to the clinical condition and the results of standard liver function tests. We based our regimen on a careful review of the literature, but this is not always illuminating with regard to the precise methodology and doses employed by others.

The importance of histological remission is based on attaining morphological appearances identical with those typifying chronic persistent hepatitis, a condition considered benign (Becker et al., 1970) and therefore differing from chronic active or subacute hepatitis, which may progress to cirrhosis and death (Baggenstoss et al., 1972; Summerskill, 1974). The frequency of relapse after the first drug-induced histological remission (Table 2) does not invalidate this end-point of therapy, since sustained remissions often follow subsequent courses of Pred or Comb (Ammon et al., 1972; Summerskill et al., 1974). We have reported elsewhere that the presence of cirrhosis requires longer periods of treatment to obtain remission and results in more frequent relapses after therapy (Ammon et al., 1973). In other studies using dose titration of steroids, cirrhosis has commonly developed or been found at necropsy (Cook et al., 1971; Mistilis et al., 1968). Cirrhosis infrequently developed with Pred-Titrad in our patients, the 
incidence being similar to other schedules, but our period of follow-up was quite short.

Designs of schedules employing variable doses of steroids do not closely resemble each other (Cook et al., 1971; Mackay, 1968; Mistilis, 1969; Page et al., 1969). Our regimen quickly secured resolution of abnormal clinical and biochemical features, but this required frequent tests (compared with other treatments) which, in other circumstances, may have necessitated numerous physician-visits. The failure of Pred-Titrad to suppress histological activity was unrelated to the duration of therapy or to the total doses of prednisone prescribed, since continued treatment failed to improve the incidence of remission. On the other hand, there were fewer sideeffects with Pred-Titrad than with Pred. While the relative contributions to this of alternate-day therapy and the lower maintenance dose of steroids involved cannot be computed, our data do show that the higher mean dose of prednisone $(20 \mathrm{mg}$ daily as opposed to $10 \mathrm{mg}$ ) necessary to procure histological remission is also responsible for a sharp increase in complications.

Earlier uncertainties concerning the efficacy of steroid therapy in CALD (Geall et al., 1968) presumably reflected inadequacies of maintenance doses chosen on the basis of suppression of clinical and biochemical abnormalities (usually between 10 and $15 \mathrm{mg}$ prednisone daily) and failure to utilize histoiogical end-points of treatment (Mackay, 1968; Mistilis, 1969), perhaps because it was considered that the histological lesions could not be reversed by therapy (Mistilis, 1968). It is still unlikely that any universally effective standard dose will be found. The amount of prednisone necessary to secure clinical and biochemical resolution with PredTitrad varied from 10-15 mg q.o.d. in our experience and a few patients treated with each of our regimens failed treatment and required even higher doses (Ammon et al., 1972; Summerskill et al., 1974).

Our design incorrectly anticipated stabilization doses for Pred-Titrad which would allow direct therapeutic comparisons with the prednisone content (10 mg daily) of Comb and result in conclusions concerning the efficacy of the azathioprine $(50 \mathrm{mg})$ component of Comb. Nevertheless, a therapeutic effect of azathioprine in combination with prednisone is likely in view of the significantly better overall response to Comb than Pred-Titrad, despite identical mean doses of prednisone (10 mg daily). Specifically, the incidence of remission in eight patients stabilized on Pred-Titrad containing the equivalent of $10 \mathrm{mg}$ or $15 \mathrm{mg}$ prednisone daily was inferior to that with Comb. Therapeutic activity ascribed to azathioprine (or to its derivative, 6-mercaptopurine) when given alone to some patients with CALD (Mistilis and
Blackburn, 1967) is not necessarily at variance with our earlier failure to show a statistical advantage of azathioprine over placebo (Soloway et al., 1972), since our observations were restricted to patients with very severe disease.

Because the therapeutic efficacy of Comb equals that of Pred, and as side-effects with Comb are significantly less, combinations of prednisone with azathioprine are to be preferred for the initial treatment for severe CALD. Contraindications to azathioprine comprise leucopenia or thrombocytopenia and sensitivity reactions. In such instances, Pred can be prescribed (Soloway et al., 1972). Pregnancy is probably contraindicated during either therapy, since both drugs may be potentially teratogenic. Regimens which include azathioprine have two disadvantages. The haemogram must be monitored regularly (Soloway et al., 1972) and little is known about the long-term actions of the drug. Azathioprine may have oncogenic properties which are at present best characterized by the development of lymphomas at a young age in individuals receiving high doses against a background of renal disease, chronic azotaemia, transplantation, and general immunosuppression (Penn and Starzl, 1972). The incidence of the relatively benign neoplasms that we found in patients taking azathioprine did not clearly exceed what might be anticipated in any series comprising the age group and follow-up spanned by our patients, and the only lymphoma developed in a patient receiving prednisone. In summary, current knowledge makes it unlikely that the smaller amounts of azathioprine necessary for treatment of CALD would be contraindicated, bearing in mind the probabilities of deterioration and death if the condition is untreated or the frequency of severe side-effects if therapy with prednisone alone is undertaken.

In conclusion, we emphasize that factors additional to the therapeutic regimen can significantly influence responses to treatment. Data analysed from the series of patients reported here show that those with SHMN are more frequently treatment failures and develop cirrhosis than those with CAH or SHB (Schalm et al., 1974) and the poorer prognosis of patients with cirrhosis is cited earlier. Most recently (Schalm et al., in preparation), we have presented our findings that patients with the hepatitis B surface antigen less often enter remission and more often fail treatment than those without.

We acknowledge with gratitude the collaboration of our patients and their home physicians, together with the invaluable assistance of Mrs. Audrey Wolf, R.N., Dr. Lila Elveback, PhD, of our Department of Statistics prepared and appropriately modified the randomization procedure (Soloway et al., 1972) 
which was carried out by Methodist Hospital Pharmacy. Prednisone (Metacorten) was kindly supplied by British Schering Corporation and azathioprine was given by Burroughs Wellcome Company.

\section{References}

Ammon, H. V., Baggenstoss, A. H., and Summerskill, W. H. J. (1972). Characterization and incidence of remission and relapse in chronic active liver disease (CALD). (Abstract). Gastroenterology, 62, 173.

Ammon, H. V., Summerskill, W. H. J., and Baggenstoss, A. H. (1973). Initial morphologic appearances determine responses to treatment of chronic active liver disease (CALD); a prospective study. (Abstract). Gastroenterology, $65,526$.

Baggenstoss, A. H., Soloway, R. D., and Summerskill, W. H. J. (1972). Chronic active liver disease. The range of histologic lesions, their responses to treatment, and their evolution. Human Pathology, 3, 183-198.

Becker, M. D., Scheur, P. J., Baptista, A., and Sherlock, S. (1970). Prognosis of chronic persistent hepatitis. Lancet, 1, 53-57.

Cook, C. G., Mulligan, R., and Sherlock, S. (1971). Controlled prospective trial of corticosteroid therapy in active chronic hepatitis. Quarterly Journal of Medicine, 40, 159-185.

Geall, M. G., Schoenfield, L. J., and Summerskill, W. H. J. (1968). Classification and treatment of chronic active liver disease. Gastroenterology, 55, 724-729.

Harter, J. G., Reddy, W. J., and Thorn, G. W. (1963). Studies on an intermittent corticosteroid dosage regimen. New England Journal of Medicine, 269, 591-596.

Mackay, I. R. (1968). Chronic hepatitis: effect of prolonged suppressive treatment and comparison of azathioprine with prednisone. Quarterly Journal of Medicine, 37, 379-392.

Mistilis, S. P. (1968). Natural history of active chronic hepatitis. 2. Pathology, pathogenesis and clinico-pathological correlation. Australian Annals of Medicine, 17, 277-288.

Mistilis, S. P. (1969). Active chronic hepatitis. In Diseases of the Liver, pp. 645-671. Edited by L. Schiff. Lippincott: Philadelphia.

Mistilis, S. P., and Blackburn, C. R. B. (1967). The treatment of active chronic hepatitis with 6-mercaptopurine and azathioprine. Australian Annals of Medicine, 16, 305-311.

Mistilis, S. P., Skyring, A. P., and Blackburn, C. R. B. (1968) Natural history of active chronic hepatitis: 1. Clinical features, course, diagnostic criteria, morbidity, mortality and survival. Australian Annals of Medicine, 17, 214-223.

Murray-Lyon, I. A., Stern, R. B., and Williams, R. (1973). Controlled trial of prednisone and azathioprine in active chronic hepatitis. Lancet, 1, 735-737.

Page, A. R., Good, R. A., and Pollara, B. (1969). Long term results of therapy in patients with chronic liver disease associated with hypergammaglobulinemia. American Journal of Medicine, 47, 765-774.

Penn, I., and Starzl, T. E. (1972). Malignant tumors arising de novo in immuno-suppressed organ transplant recipients. Transplantation, 14, 407-417.

Schalm, S. W., and Summerskill, W. H. J. (1975). Special features of chronic active liver disease (CALD) associated with hepatitis $B$ surface antigen $\left(\mathrm{HB}_{\mathbf{s}} \mathrm{Ag}\right)$. (Abstract). Presented at the annual meeting. American College of Physicians, 1975. (In preparation).

Schalm, S. W., Summerskill, W. H. J., Korman, M. G., and Baggenstoss, A. H. (1974). Subacute and chronic active hepatitis compared. (Abstract). Gastroenterology, 67, A-49/826.

Siegel, R. R., Luke, R. G., and Hellebusch, A. A. (1972). Reduction of toxicity of corticosteroid therapy after renal transplantation. American Journal of Medicine, 53, 159-169.

Soloway, R. D., Baggenstoss, A. H., and Schoenfield, L. J. (1971). Observer error and sampling variability tested in evaluation of hepatitis and cirrhosis by liver biopsy. American Journal of Digestive Diseases, 16, 1082-1086.

Soloway, R. D., Summerskill, W. H. J., Baggenstoss, A. H., Geall, M. G., Gitnick, G. L., Elveback, L. R., and Schoenfield, L. J. (1972). Clinical, biochemical and histological remission of severe chronic active liver disease: a controlled study of treatments and early prognosis. Gastroenterology, 63, 820-833.

Summerskill, W. H. J. (1973). Chronic active liver disease. Evaluation and treatment. Viewpoints on Digestive Disease, 5, no. 3.

Summerskill, W. H. J. (1974). Chronic active liver disease reexamined: prognosis hopeful. Gastroenterology, 66, 450-464

Summerskill, W. H. J., Ammon, H. V., and Baggenstoss, A. H. (1974). Treatment of chronic hepatitis. In The Liver and its Diseases, pp. 216-226. Edited by F. Schaffner, S. Sherlock, and C. M. Leevy, Intercontinental Medical Book Corp.: New York. 